\title{
The brain drain: some evidence from European expatriates in the United States*
}

\author{
Gilles Saint-Paul \\ GREMAQ-IDEI, Université de Toulouse 1, CEPR, and IZA \\ September 6, 2004
}

ABSTRACT: This paper uses U.S. Census data from 1990 and 2000 to provide evidence on the labor market characteristics of European-born workers living in the US. It is found that there is a positive wage premium associated with these workers, and that the highly skilled are over-represented compared with the source country, more so, when one moves up the skill ladder.

JEL: J31, J61

Keywords: Brain Drain, Migration, Europe.

*I am grateful to Ahmed Tritah for excellent research assistance. This project has benefitted from funding by the European Commission under the DAEUP project. 


\section{Introduction}

Since 1995, Europe has stopped closing the gap with the U.S. Growth has been faster in America as it reaped the benefits of full employment and new information technologies. Europe is worried about its aging population, its ability to adapt to technical change, the burden of its welfare state and the pains of labor market deregulation. Among the worries is the fear that it might be losing its most talented workers to the United States. Stories about succesfull expatriates in the Silicon valley or at top academic places abound. Many European politicians and businessmen now complain that they cannot compete because of taxes and regulations in order to attract the best workers ${ }^{1}$.

This paper provides some evidence about the brain drain from Europe to the US². It uses US census data for 1990 and 2000 to measure the characteristics of European expatriates and see how they fare in the US labor market.

The data confirm the presumption that the skill composition of expatriates is much better than in the source countries. The quantitative significance of that, however, is open to debate, as the total number of expatriates ranges between 0.5 and $1 \%$ of the population. If one takes the view that labor is a small number of homogeneous inputs, such as skilled labor and unskilled labor, then our back-of-the envelope computations suggests a moderate adverse effect of the brain drain on inequality and income in home countries, with say a 2-3\% increase in the relative wage of the skilled and a $0.5-0.7 \%$ decline in GDP per capita. On the other hand, if one assumes that labor is not a collection of homogeneous inputs, but instead that very talented in-

\footnotetext{
${ }^{1}$ See for example the François-Poncet (1999), Mahroum (1999)..

${ }^{2}$ See Becker et al. (2002) for an analysis of the brain drain from Italy to the rest of Europe.
} 
dividuals are crucial for innovation, business formation, and management ${ }^{3}$, the loss could be considerably bigger, but it is much harder to estimate (An interesting first step is Zucker et al. (2003)). My speculative extrapolations suggest that the proportion of European people who "matter", who are in the U.S. could be as high as $50 \%$; that is huge and can in principle have dramatic consequences on Europe's growth potential-while such a number can be disputed, casual observation suggests that in my field (research in economics), it is about right.

\section{Data}

The data I use is the U.S. census, for years 1990 and 2000. I look at the demographic and economic characteristics of Europeans living in the U.S. in both samples. Using both years can in principle tell us interesting things about the dynamics of the brain drain.

The only difficulty in using census data to learn about the expatriates is how to define them. Citizenship is clearly not a very good indicator, as many expatriates have US citizenship. We prefer to use the country of birth as our defining variable, It is not immune to criticism either especially as it includes people born to american parents abroad, children of US soldiers, and so forth, However, we assume that this is a reasonably small group and it is not a prior expected to bias the results in any significant direction. We limit the analysis to five continental countries (Belgium, France, Spain, Italy, and Germany) plus the United Kingdom, which we expect to follow a different logic given its historical ties and community of language with the United States.

\footnotetext{
${ }^{3}$ Stephan and Levin (1999) document the exceptional contributions to US science by foreign-born researchers.
} 


\section{Basic demographics}

Table 1 reports the number of citizens born in each of the six countries we look at and aged between 25 and 64 (thereafter refered to as "working age") in the two US censuses, and what share of the working age-population in the country of origin they amount to. These fractions vary between a small $0.36 \%$ in Spain to $1.66 \%$ in the UK. That suggests that the macreconomic effects of the brain drain are not likely to be very large, but they need not be insignificant either.

If the distribution of workers characteristics is the same among emigrants as in the home country labor force, emigration just reduces the size of the home country labor force homothetically, with no effects on wages in the long run, and a positive effect in the short run as there is more capital per capita in the source country. However, if some groups are disproportionately represented among expatriates, emigration may have non negligible effects on the structure of wages. Suppose, for example, that we have two types of workers, skilled $(H)$ and unskilled $(L)$, and that initially the skilled account for $10 \%$ of employment but get $30 \%$ of total income. With a Cobb-Douglas production function, that would imply ${ }^{4} Y=A H^{\alpha} L^{1-\alpha}$, with $\alpha=0.3$ and $H / L=1 / 9$. Now, if $1 \%$ of the population goes abroad and $30 \%$ of them are skilled, the $H / L$ ratio falls by some $2.2 \%$. That means that the wage gap between the skilled and the unskilled in the home country will go up by $2.2 \%$ too, with $10.66 \%$ wage reduction for the unskilled and a $1.54 \%$ wage gain for the skilled. One also finds a $0.4 \%$ drop in GDP per capita. That is not huge, but not negligible either. If the exodus is now highly concentrated among the skilled, say if all those who leave are skilled, the $H / L$ will fall by $10 \%$, and so will the relative wage of the unskilled, whose absolute wage

\footnotetext{
${ }^{4}$ That is the long-run production function, where capital is left to adjust and thus ignored.
} 
falls by $3 \%$, while that of the skilled goes up by $7 \%$. That is about the upper bound of how the wage distribution can widen if a country loses $1 \%$ of its workforce. As for GDP per capita, it would then fall by $2.1 \%$.

A comparison between the two census years also reveals that the drain is accelerating, but not dramatically; in all countries except Italy, a slightly higher fraction of the home working age population is working in the US in 2000 than in 1990. In the case of Italy, a traditional source of low-skilled immigrants, the faction is actually falling, reflecting the phasing out of lowskilled migration from Italy to the United States. These number suggest that there is no strong acceleration in the latter part of nineties, and that the phenomenon is of the same order of magnitude as in the eighties.

\begin{tabular}{lllll}
\hline \hline & 1990 & & 2000 \\
\hline Country & Number & \% of home pop. & Number & \% of home pop \\
Belgium & 21561 & 0.45 & 22631 & 0.62 \\
France & 115245 & 0.4 & 133873 & 0.43 \\
UK & 450804 & 1.53 & 524922 & 1.656 \\
Spain & 57375 & 0.29 & 78061 & 0.36 \\
Italy & 344406 & 1.15 & 303685 & 0.93 \\
Germany & 657937 & 1.40 & 720555 & 1.54 \\
\hline \hline
\end{tabular}

Table 1 - The European born population aged 25-64 in the US.

In Table 2 we get more information by looking at the age distribution of Europeans living in the US. We see that for France, the UK, Italy and Germany, there are actually fewer workers aged 25-34 living in the United States in 2000 than in 1990. In at least two of these cases (France and Germany), it seems to be due to a burst of emigration from this group in the 1980s, as it represent an abnormally high share of the expatriate population. Nevertheless, this fall in the number of expatriates in that age group is somewhat paradoxical in light of the overall increase in the number of expatriates. Conventional wisdom would suggest that (i) People go to the US 
when young, (ii) there was more emigration from Europe to the US in the 1990s than in the 1980s, and (iii) there is substantial net return migration as people get older. In fact, while entry of young workers seems to have fallen in the 1990s relative to the 1980s (except for Belgium and Spain), there is substantial entry of older workers in the $1980 \mathrm{~s}$, so that there is no evidence of net return migration. There was enough of an inflow of migrants in the older cohorts so as to offset the fall of migrants in the younger one. That is clear from Table 3, which performs a cohort analysis, comparing the size of an age group living in the US in 2000 with the size of that same cohort in 1990. The cohorts aged between 25 and 44 living in the US increased in size in the 1990s, and even the 45-54 cohorts barely decreased. Of course, that may hide a lot of two-way movements between Europe and the US. Yet, for a policymaker who worries about the brain drain, that suggests that return migration is on net not to be counted on; those who return are quite likely to go back and definitive return is deferred to retirement time.

One can only speculate about why the younger age group has declined in size at the same time as older groups have increased. The effect is too large to be explained by a reduction in the size of the corresponding cohort in the source country due to aging. A deterioration of foreign language skills learned at school does not square with the fact that the effect is also observed in the UK. 


\begin{tabular}{llllll}
\hline \hline & & $25-34$ & $35-44$ & $45-54$ & $55-64$ \\
\hline Belgium & 1990 & $4.7(22.1)$ & $6.3(29.0)$ & $4.6(21.4)$ & $5.9(27.4)$ \\
& 2000 & $6.1(27.1)$ & $5.2(22.8)$ & $6.8(30.1)$ & $4.5(19.9)$ \\
\hline France & 1990 & $47.7(41.4)$ & $25.7(22.3)$ & $19.6(17)$ & $22.3(19.4)$ \\
& 2000 & $32.4(24.2)$ & $54.3(40.7)$ & $27.4(20.5)$ & $19.8(14.8)$ \\
\hline United Kingdom & 1990 & $125.8(27.9)$ & $122.8(27.2)$ & $111.9(24.8)$ & $90.3(20.0)$ \\
& 2000 & $117.9(22.5)$ & $163.4(31.1)$ & $130.1(24.8)$ & $113.6(21.6)$ \\
\hline Spain & 1990 & $20.7(36.1)$ & $12.4(21.7)$ & $12.7(22.1)$ & $11.6(20.1)$ \\
& 2000 & $27.6(35.4)$ & $25.0(32)$ & $13.7(17.6)$ & $11.8(15.1)$ \\
\hline Italy & 1990 & $59.8(17.4)$ & $90.0(26.1)$ & $94.0(27.3)$ & $100.7(29.2)$ \\
& 2000 & $39.4(13.0)$ & $71.4(23.5)$ & $96.8(31.9)$ & $96(31.6)$ \\
\hline Germany & 1990 & $214.7(32.6)$ & $172.8(26.3)$ & $141.0(21.4)$ & $129.5(19.7)$ \\
& 2000 & $176.9(24.6)$ & $236.0(32.8)$ & $170.3(23.6)$ & $137.3(19.1)$ \\
\hline \hline
\end{tabular}

Table 2-The age distribution of expatriates in 1990 and 2000

(thousands, percentage of US census expatriate population in parentheses)

\begin{tabular}{llll}
\hline \hline Country & \multicolumn{3}{l}{ Cohort in 2000 } \\
\hline \multirow{3}{*}{ Belgium } & $35-44$ & $45-54$ & $55-64$ \\
France & +10.6 & +7.9 & -2.2 \\
United Kingdom & +13.8 & +6.6 & +1 \\
Spain & +30.0 & +7.0 & +1.5 \\
Italy & +20.8 & +10.5 & -7.1 \\
Germany & +19.4 & +7.6 & +2.1 \\
\hline \hline
\end{tabular}

Table 3 - Inflows by cohorts

The next two tables compare the employment rates of expatriates with those of other US residents as well as the unemployment rate in their countries of birth. We find that for men, employment rates for European expatriates are higher than average in the US labor market, and therefore substantially higher than in their home countries. For women, the employment rate is higher than in their home countries but lower than in the US labor market. 
These results are not surprising: one does not emigrate to a country like the U.S. if one does not have good employment prospects there. But, to the extent that it signals greater employability of expatriates relative to stayer, that effect should also be added when computing the adverse effects of the brain drain of GDP per capita.

\begin{tabular}{l|l|l|ll}
\hline \hline \multicolumn{2}{l|}{1990} & \multicolumn{2}{l}{2000} \\
\hline & US residents & Home country & US & Home \\
\hline Belgium & 87.4 & 77.1 & 87.5 & 78.1 \\
France & 88.3 & 80.5 & 85.1 & 78.5 \\
UK & 89.7 & 84.2 & 87.5 & 82.2 \\
Spain & 85.4 & 79.5 & 80.8 & 80.2 \\
Italy & 83.6 & 81.4 & 76.7 & 75.9 \\
Germany & 88.4 & 80.1 & 85.5 & 77.4 \\
\hline USA & & 85.3 & \multicolumn{3}{c}{85.2} \\
\hline \hline
\end{tabular}

Table 4-Employment rates, men

\begin{tabular}{lll|ll}
\hline \hline & 1990 & & 2000 & \\
\hline \multirow{3}{*}{ Belgium } & US residents & Home country & US & Home \\
France & 65.0 & 44.3 & 61.7 & 57.5 \\
UK & 64.3 & 57.4 & 65.9 & 62.5 \\
Spain & 60.9 & 62.0 & 64.8 & 66.9 \\
Italy & 53.3 & 32.7 & 61.4 & 45.1 \\
Germany & 64.0 & 59.7 & 56.6 & 43.2 \\
\hline USA & 51.7 & 65.8 & 60.7 \\
\hline \hline
\end{tabular}

Table 5 - Employment rates, women

\section{Education}

We now turn to the observable dimensions of worker quality, in particular education. We are especially interested in highly skilled people, and therefore 
will focus on the most advanced degrees. Table 5 lists the share of expatriate population with tertiary education. As can be seen, it is far larger than in the US labor market at large and even larger than in the corresponding home country. For example, in 2000, 56 \% of French-born workers living in the US had a college degree, against $21 \%$ in France. Most remarkably, the education level of the expatriates seems to have improved during the nineties at an even higher pace than in the source countries, While the fraction of the source population with a college degree increased by $9,7,10,12,7$ and 11 points in Belgium, France, the UK, Spain, Italy, and Germany, respectively, among expatriates it has gone up by $12,14,11,14,8$, and 7 points. Thus only in Germany does the home population level increase faster than for expatriates.

\begin{tabular}{lll|ll}
\hline \hline & 1990 & & 2000 & \\
& US census & Home country & US census & Home country \\
\hline Belgium & 47.6 & 17 & 59.6 & 26 \\
France & 42.7 & 14 & 56.1 & 24 \\
UK & 38.9 & 15 & 49.2 & 25 \\
Spain & 30.6 & 9 & 44.1 & 21 \\
Italy & 17.1 & 6 & 25.7 & 13 \\
Germany & 34.6 & 17 & 41.9 & 28 \\
\hline US & 29.7 & & 33.8 & \\
\hline \hline
\end{tabular}

Table 6 - Fraction of the expatriate population with tertiary education, vs. corresponding fraction in home country and whole US census.

These data confirm that the expatriates are heavily selected among the most educated workers. This skewness increases when one moves up the skill ladder. Table 7 reports the fraction of expatriates who have a Ph.D. and compares it to the average US workers. Unfortunately, we do not have the corresponding figures for the European countries, but they are unlikely to be higher than in the United States. 


\begin{tabular}{ll|l}
\hline \hline & 1990 & 2000 \\
\hline Belgium & 4.33 & 5.78 \\
France & 3.1 & 4.9 \\
UK & 3.2 & 3.9 \\
Spain & 2.7 & 4.6 \\
Italy & 0.96 & 2.0 \\
Germany & 1.72 & 2.39 \\
\hline US & 0.82 & 0.98 \\
\hline \hline
\end{tabular}

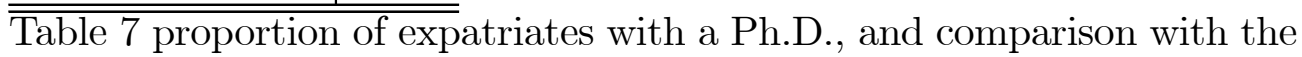
US labor market

The fraction of expatriates who have a Ph.D. is growing more rapidly among expatriates than among americans. In 2000, it is 2 to 6 times higher than in the US population. The phenomenon is even more salient if one only looks at those who arrived in the US less than 10 years before the census. The proportion of Ph.Ds among them can be as high as $10 \%$ (Table 8).

\begin{tabular}{ll|l}
\hline \hline & 1990 & 2000 \\
\hline Belgium & 8.06 & 10.53 \\
France & 8.2 & 8.6 \\
UK & 5.4 & 5.3 \\
Spain & 4.0 & 9.4 \\
Italy & 2.9 & 8.6 \\
Germany & 4.9 & 6.8 \\
\hline US & 0.82 & 0.98 \\
\hline \hline
\end{tabular}

Table 8 - Percentage of workers with PhDs among newly arrived workers

Assuming the average proportion of expatriates having Ph.D. will converge to something like $10 \%$, which is an upper bound, that the proportion of Ph.Ds in the source population is $0.5 \%$ (about half the US level), and that 0.5-1 \% of a typical European country's citizens live in the United States, we see that the share of a country's Ph.Ds working in the US could go as far as 10-20\%. Furthermore, there are presumptions that these are more talented 
than the home country Ph.D., but it is very hard to measure from these data. Finally, from the point of view of measuring the economic consequences of the brain drain, we also want to know what the contributions of $\mathrm{PhDs}$ to GDP is, both in Europe and in the US.

Suppose that, on the basis of Table 6, we speculate that, for any segment of the distribution of income, the fraction of expatriates is twice higher in the first quartile of the ability distribution than in the population as a whole, and that we apply that to Ph.Ds. Then in our stylized example that would mean that as many as 20-40\% of the $25 \%$ best doctors could be in the United States, depending on the total expatriation rate. Suppose now that we follow Zucker et al (2003) and assume that those who really matter (in that they exert significant externalities of innovation and firm creation) are the "star" people, which are the top $5 \%$ of Ph.Ds (this is about the fraction of stars in Zucker et al's sample of biotechnologists); that would more or less correspond to the top quartile of the top quartile. Under our extrapolation, that would mean that $40-80 \%$ of the European stars would be in the United States. A potential implication, for example, is that the number of new products and processes being invented in Europe would be about twice higher absent the brain drain.

\section{Wages}

Education, as measured by the number of years, is of course not the only relevant characteristic that people bring to the labor market. There are other dimensions of skills that are not observable to the statistician (one of them being the quality of education). How are Europeans selected according to those dimensions? A natural way to answer that question is to estimate a standard wage equation and enter dummies to find out if, given their observable characteristics, Europeans earn more than their counterpart in the US 
labor market.

Table 9 reports the results of such a regression for both census years. The "European premium" is uniformly positive and significant, ranging from 2 to $16 \%$. It is quite small for the German-born. During the nineties, it has risen sharply for the French, the British, and moderately for the Spaniards. It has fallen for Italians, Belgians, and Germans. These trends may be due to changes in the distribution of expatriates' unobservable characteristics or to changes in the demand for specific goods they produce. It may also be that average unobserved worker quality follows a different trend in the home countries as compared to the US, but one does not see why this should be so (trends in international comparisons of students achievements do not exhibit such patterns). My favored explanation is that positive selection of migrants in the dimension of unobservable worker quality has intensified during the nineties, which may be explained by the general increase in the returns to skills that has been documented in the US but is much less salient in Europe.

\begin{tabular}{lll}
\hline \hline Country & 1990 & 2000 \\
\hline France & $4.9(19.4)$ & $10.7(44.8)$ \\
Italy & $16.7(113.0)$ & $11.5(69.0)$ \\
Germany & $3.12(29.5)$ & $2.14(20.6)$ \\
United Kingdom & $12.6(99.1)$ & $16.3(135.7)$ \\
Spain & $6.2(17.15)$ & $7.9(24.3)$ \\
Belgium & $15.1(24.1)$ & $13.8(23.5)$ \\
\hline Table 9 - Wage premia for European expatriates & \\
(t-statistics in parentheses)
\end{tabular}

A relevant question is: how does the wage premium vary across educational levels? Answering it would give valuable hints about the nature of emigration. If the wage premium is higher for less educated workers, that suggests that institutions in their home countries are not very good at remunerating their skills, either because the educational system inadequately fails 
to certify them (for example, a good mathematician does not find the appropriate curriculum), or because the labor market works poorly at rewarding skills other than education (for example if there are binding collective agreements who do not give "points" for such skills). On the other hand, if we find that the wage premium is higher for more educated workers, that suggests that among the most educated, the better qualified have an even greater probability to move to the US, confirming that selection operates more strongly when one moves up the skill ladder. Such a finding would be roughly consistent with the Borjas (1987) model of migration.

For this reason I have run wage regressions where the workforce is split in only two educational categories (tertiary vs. not tertiary), and use an interaction term between the tertiary education dummy and the place of birth dummies. The results are reported in Table 10. Note that the estimated premia are higher than when the specification corresponding to the preceding Table is used. In 1990, the wage premium was higher for college graduates than for other workers for the French-born and the British-born, and smaller for others. In 2000, it is higher for all countries of origin. Hence, in 2000, selection of the best workers is more intense among college-graduates than among others.

\begin{tabular}{lll|ll}
\hline \hline Country & 1990 & & 2000 & \\
\hline & No tertiary & Tertiary & No tertiary & Tertiary \\
France & 9.8 & 14.6 & 12.4 & 23.3 \\
Italy & 9.1 & 7.25 & 9.0 & 9.0 \\
Germany & 8.7 & 5.0 & 6.15 & 7.8 \\
United Kingdom & 20.9 & 24.7 & 23.6 & 27.9 \\
Spain & 8.8 & 3.7 & 11.2 & 13.9 \\
Belgium & 24.2 & 19.2 & 16.9 & 26.2 \\
\hline
\end{tabular}

$\overline{\overline{\text { Table }} 10 \text { - Estimated wage premia for expatriates with and without }}$ tertiary education. 


\section{Entrepreneurs}

In light of the view that the brain drain is a matter of concern because a number of expatriates are exceptional individuals, we may ask wether entrepreneurs over-represented among expatriates. The following Table reports the proportion of workers who have an entrepreneurial activity, and compares it to the US labor market.

\begin{tabular}{lll}
\hline \hline & 1990 & 2000 \\
\hline Belgium & 13.18 & 11.51 \\
France & 10.67 & 11.39 \\
UK & 9.84 & 10.55 \\
Spain & 10.96 & 10.29 \\
Italy & 13.42 & 14.21 \\
Germany & 9.85 & 9.39 \\
\hline US & 8.08 & 9.08 \\
\hline \hline
\end{tabular}

$\overline{\overline{\text { Table } 11-\text { The proportion }}}$ of entrepreneurs (\%).

The proportion of entrepreneurs among expatriates is slightly higher than among americans and is stable over time. How does it compare to the corresponding proportion in the home country? While such a comparison should be taken with caution, the Global Entrepreneurship Monitor (2002) suggests that it is about half lower in Europe than in the US. If one takes that proportion seriously, then European expatriates are a bit more than twice likely to be entrepreneurs than those who remain in Europe. That does not, obviously, imply that they are very skilled, among them are shopkeepers, taxi drivers, etc, and gives us no information on the relative quality of European entrepreneurs based in the U.S. vs. those based in Europe. And there are problems with comparing entrepreneurship data cross countries. Nevertheless, these numbers are suggestive that a disproportionate fraction of entrepreneurs are likely to emigrate to the U.S. 


\section{Conclusion}

This paper has provided a number of stylized facts about European-born immigrants in the US labor market. We have found that their skill level is substantially higher than in Europe, and that they compare favorably to Americans of similar educational levels in terms of unobservable quality, since there is a positive wage premium for European-born participants in the US labor market. European expatriates also have a high employment rate and a high proportion of entrepreneurs. They are several times more likely to have a Ph.D. than the average U.S. labor market participants, and presumably than the average European resident. The proportion of Ph.Ds among recent expatriates can be as high as $10 \%$.

This highly biased composition of European expatriates has to be balanced against their relative small numbers - about $0.5-1 \%$ of the home population. If one takes a rather homogeneous view of the labor market, that suggest that the economic consequences of the brain drain on the home country cannot be dramatic - it implies a moderate increase in inequality and perhaps a $0.5 \%$ reduction in GDP per capita. These numbers could be considerably higher if one considers that a country's potential for growth and innovation is chiefly determined by key individuals - scientists, managers and entrepreneurs - and that a large proportion of the most talented have moved to the U.S. 


\section{REFERENCES}

Becker, S., A. Ichino and G. Peri (2002), "How large is the brain drain from Italy?", Munich University Working Paper.

Borjas, George J. (1987), "Self-Selection and the Earnings of Immigrants"

American Economic Review, Volume 77, Issue 4, September 1987, Pages $531-553$

François-Poncet, J. (1999), "La fuite des cerveaux : mythe ou réalité ?" Report to the French Senate, http://www.senat.fr/rap/r99-388/r99-388.html

Mahroum, S. (1999) "Europe and the challenge of the brain drain", IPTS Report 29

Global Entrepreneurship Monitor Consortium (2002), Global Entrepreneurship Monitor

Stephan, P. and S.G. Levin (1999), "Exceptional contributions to US Science by the foreign-born and foreign-educated", Science, 285

Zucker, Lynne G.; Darby, Michael R.; Brewer, Marilynn B (1998), "Intellectual Human Capital and the Birth of U.S. Biotechnology Enterprises", American Economic Review, Volume 88, Issue 1, March 1998, Pages 290-306 